\title{
FEEDING EVALUATION OF MICROCRUSTACEA (CLADOCERA): RESPONSES TO VARIATIONS IN CELL VOLUME OF GREEN AND BLUE-GREEN ALGAE
}

\author{
ISMAIL, A. H. ${ }^{1^{*}}-$ MILLS, $\mathrm{S}^{2}-$ RECKNAGEL, $\mathrm{F}^{2}$

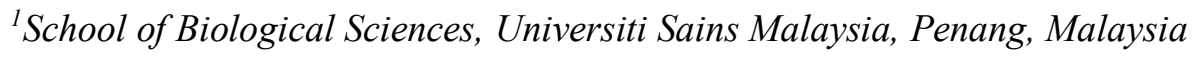 \\ ${ }^{2}$ School of Biological Sciences, University of Adelaide, Adelaide, Australia \\ ${ }^{*}$ Corresponding author \\ e-mail:azmahanim@usm.my; phone:+604-653 6170; fax:+604-6565125 \\ (Received 12 $2^{\text {th }}$ Mar 2019; accepted $1^{\text {st }}$ May 2019)
}

\begin{abstract}
The grazing rate of three zooplankton species; Daphnia carinata, D. lumholtzi and Ceriodaphnia cf. quadrangula on six algal species at three concentrations are described in this paper. The effect of food density on ingestion rate was assessed by adding a suspension of algae to the tumblers and following the changes in concentration in the tumbler as the cladocerans consumed the suspension. Samples were taken and algal densities were measured every 15 minutes with a spectrophotometer. This study aimed to examine the role of cladoceran as grazers of algae under laboratory conditions. D. carinata removed algal cells at higher rates than the other two species when feeding in unialgal suspension. Quantitative differences in rate of food intake were found in suspensions of Ankistrodesmus falcatus, Scenedesmus obliquus, Chlorella vulgaris, Chlamydomonas reinhardtii, Anabaena circinalis and Microcystis flos-aquae. The small cells contributed by far the greatest fragment of green algae ingested by grazers. Filamentous $A$. circinalis and colonial M. flos-aquae can also be utilized by the grazers though the species was previously reported to have lethal toxic effects on cladocerans. Therefore, a management strategy using cladocerans for controlling undesirable cyanobacteria in aquatic ecosystem is contemplated to be necessary in the future.
\end{abstract}

Keywords: grazing, zooplankton, Daphnia, Ceriodaphnia, ingestion rate

\section{Introduction}

Zooplankton grazing is currently facing a crucial phase as the changes in the grazer population translate into changes in ecosystem properties, particularly in the phytoplankton biomass (Horn, 1981; Elser, 1992). Thus, it has attracted a lot of attention among scientists and has inspired them to conduct more research and experimental investigations into the plankton ecology. Measuring feeding rates of herbivorous zooplankton is important in order to understand the interaction between phytoplankton and zooplankton. Even though zooplankton grazing has been studied in laboratories worldwide, in Australia, little information is available on the subject. Zooplankton grazing directly affects the phytoplankton structure and changes the algal growth rates (Lampert et al., 1986). Algal losses in the aquatic ecosystems are caused by many factors such as grazing, sinking, parasitism, and nutrient levels (Tilman et al., 1982; Finkel et al., 2010). However, this paper focuses on zooplankton grazing through measurements in the laboratory as this approach has been known to be the best to estimate the increase and decrease of the algal population. The most important advantage of the laboratory method is the food type, food concentration quality and densities of grazers can all be defined by the researcher. Comprehensive laboratory determination of cladocerans feeding rates is essential to define the role of these important grazers in the freshwater ecosystems. 
Food uptake of suspension feeders can usually be described by the ingestion rate (IR). Ingestion rate or feeding rate is expressed as the amount, number or biomass of food cells consumed by an animal in a time interval (Wirtz, 2013). Zooplankton ingestion rate increases with food concentration. It increases up to about 100,000 cells $\mathrm{mL}^{-1}$ after which, a plateau will be reached; body length will increase and the body temperature will rise up to $20^{\circ} \mathrm{C}$ (Burns and Rigler, 1967).

In terms of food, zooplankton require high quality food with appropriate size range, to allow them to grow healthily in their ecosystem. Therefore, food size is an important factor related to cladoceran feeding. Nonetheless, not all phytoplankton cells are suitable for ingestion. Often, they refuse to feed on algae that are inedible, toxic and are in the form colonies or filaments. Furthermore, the biochemical composition, the cell wall thickness and the digestibility of algae may affect the growth and the species composition of cladoceran. Several studies have shown that different species of cladoceran have different preferences in terms of food (Bogdan and Gilbert, 1984; Knisely and Geller, 1986). Consequently, food size preferences affect their body size (Urabe et al., 1996).

In general, this study aimed to examine the role of cladoceran as grazers of algae under laboratory conditions. More specifically, it was the aim of the study:

- To determine the grazing rates of three different species of cladoceran and density of unialgal populations;

- To determine if cladocerans' algal grazing is size selective;

- To compare the feeding preferences of cladocerans between green and blue green algae.

\section{Materials and Methods}

Two medium cultures have been used in this study; AlgaBoost $\mathrm{f} / 2$ from AusAqua Pty. Ltd. as green algae medium culture and BG - 11 based on Rippka et al. (1979) for blue-green algae culture. Algae collection was obtained from cultures maintained by the SAW and Commonwealth Scientific \& Industrial Research Organisation (CSIRO). Six species of algae were used in the grazing experiments, namely Ankistrodesmus falcatus, Chlamydomonas reinhardtii, Scenedesmus obliquus, Chlorella vulgaris, Anabaena circinalis and Microcystis flos-aquae. Algae were cultured by the method described by Hoff and Snell (1987) and Kilham et al. (1998).

Cell biovolume is the most common approach used to estimate biomass of phytoplankton. The calculation of biovolume was based on geometric approximation, calculated from microscopically measured linear dimensions (Hillebrand and Sommer, 1996). Altogether, 360 cells from each species were measured and the cell sizes were grouped into various size classes. Then, the median of measured linear dimensions of the biovolume were calculated as proposed by Hillebrand et al. (1999), not as a median or mean value of a set of individually calculated biovolumes. In this experiment, the value was expressed in cell volume, rather than cell concentration as the unit will standardize the different sizes of algae.

Wild Daphnia carinata, D. lumholtzi and Ceriodaphnia cf. quadrangula were collected from Myponga and South Para Reservoirs and reared or cloned over at least 30 generations in the laboratory. Cladocerans collected from the wild were placed in Petri dishes under a dissecting microscope for sorting. Each organism was separated using T-pipette and transferred into six well plates containing filtered lake water. The 
entire set up was placed in a lighted cabinet at $20^{\circ} \mathrm{C}$ and light regime for $10: 14 \mathrm{hr}$ light and dark. To maintain the uniformity of algal cells, the plates were gently agitated by hand twice a day. The plates were incubated in a lighted cabinet at approximately $1000-1500$ lux and checked daily for clonal neonates. At least five individuals were present in the cell, the population was then transferred into a $50 \mathrm{~mL}$ falcon tube filled with filtered water and algae culture using a $10 \mu \mathrm{L}$ pipette. Cultures in falcon tubes were incubated at the same temperature and light regime as indicated above. Cultures were then replenished once a week by removing $25 \mathrm{~mL}$ of media and adding $25 \mathrm{~mL}$ of 1:1 filtered lake water and algae. Once the culture was established, it was transferred to approximately $6 \mathrm{~L}$ aquarium containing lake water (Fig. 1). The zooplankton were fed with a mixed culture of algae (Ankistrodesmus falcatus, Scenedesmus obliquus and Chlorella vulgaris) every two days (Fig. 2).

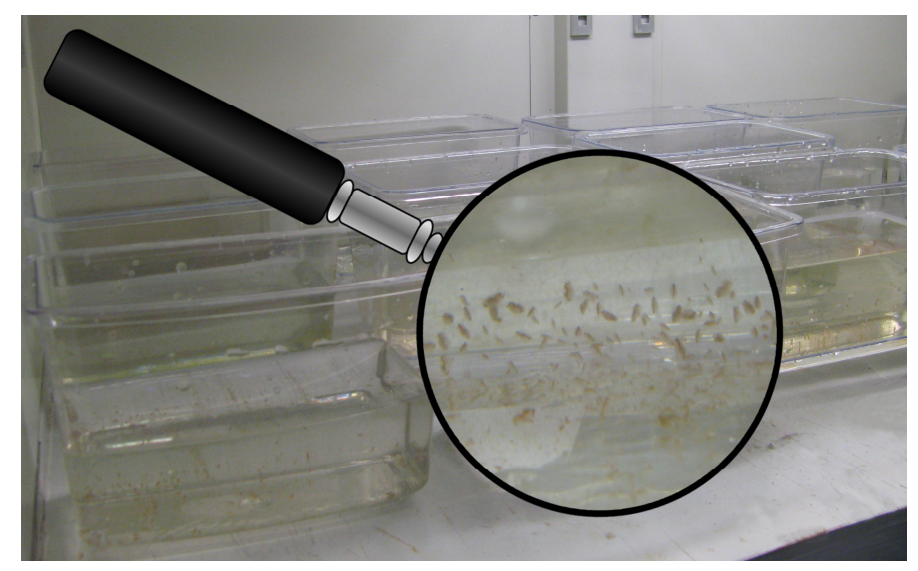

Figure 1. Zooplankton culture

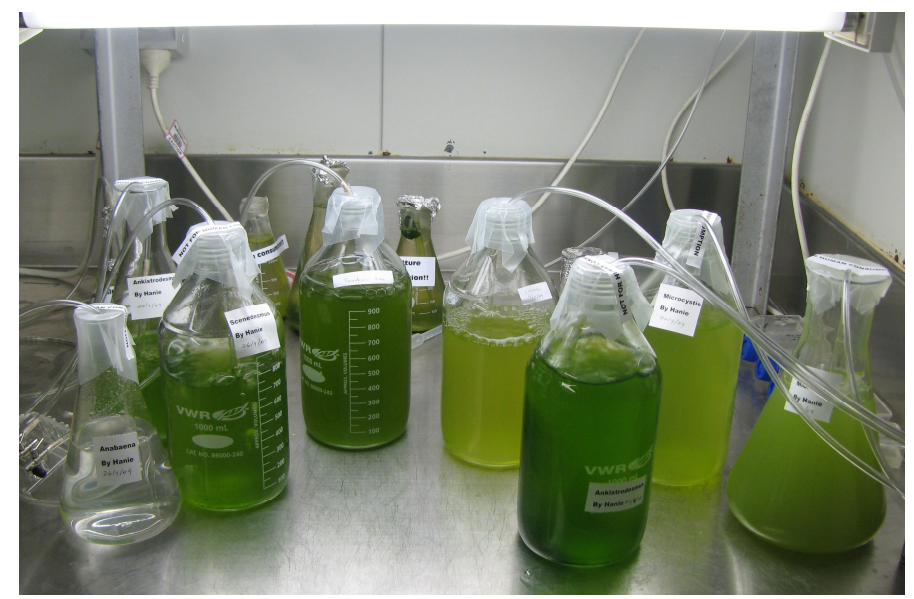

Figure 2. Algae culture

In the grazing experiments, individuals with the largest adult length (Daphnia carinata, $3.4-3.8 \mathrm{~mm}$; D. lumholtzi, $1.2-1.3 \mathrm{~mm}$; and Ceriodaphnia cf. quadrangula, $0.65-0.75 \mathrm{~mm}$ ) were used. The animals were acclimatized to the experimental temperature of $20^{\circ} \mathrm{C}$ for 24 hours before experiments in $50 \mathrm{~mL}$ of filtered lake water. Then, five adults were transferred to the $50 \mathrm{~mL}$ tumbler filled with filtered 
lake water (Fig. 3), enriched with an appropriate suspension of algae (Ismail et al., 2015). Five tumblers without animals served as the control sample. The experiments were run for two hours in a temperature-controlled cabinet at $20^{\circ} \mathrm{C}$ in the laboratory at $980-1045$ lux.

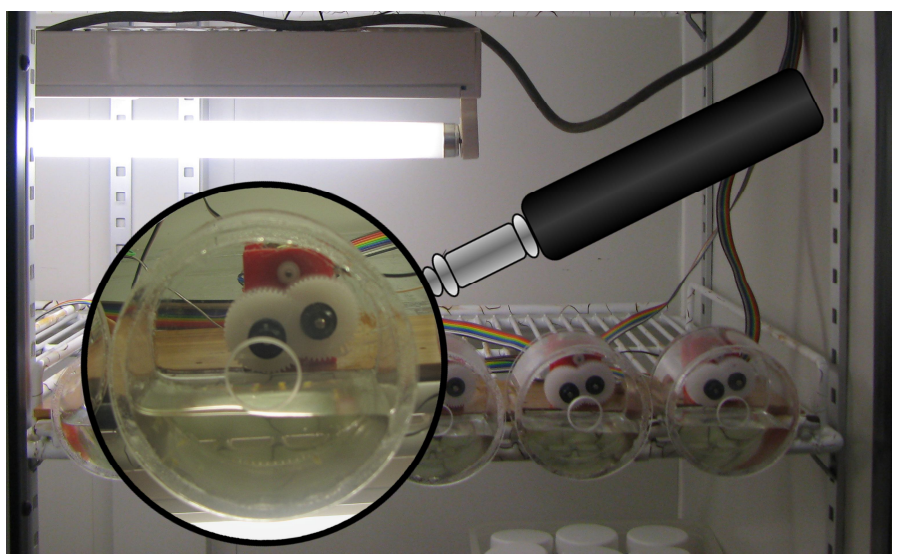

Figure 3. Rotating tumblers filled with filtered lake water, enriched with an appropriate suspension of algae

The effect of food density on ingestion rate was assessed by adding a suspension of algae to the tumblers following the changes in concentration in the tumbler as the cladocerans grazed the suspension down. Ingestion rate of cladocerans were measured every $15 \mathrm{~min}$. All counts were made in five replicates using a spectrophotometer (Model 340). The instrument was adjusted to the desired wavelength such as $470 \mathrm{~nm}$ for green algae and $645 \mathrm{~nm}$ for cyanobacteria. Ingestion rate was calculated according to the formula in Frost (1972). There were three different cell concentrations at which ingestion rate was measured. Each concentration was replicated five times. The initial concentration of algae was the same for all species used which were $1.5 \times 10^{6} \mu \mathrm{m}^{3} / \mathrm{mL}$, $3.0 \times 10^{6} \mu \mathrm{m}^{3} / \mathrm{mL}$ and $4.5 \times 10^{6} \mu \mathrm{m}^{3} / \mathrm{mL}$. The tumblers were rotated at $1.5 \mathrm{rpm}$ throughout the 2-hr experiment to minimize the sedimentation of algae. The ingestion rate was analysed using 3-way ANOVA to test the effects of the three cladocerans species, three food types and three concentrations for the eight time intervals. Significant differences among groups were tested using Tukey HSD test.

\section{Results}

The results of the grazing experiments on unialgal suspension were graphically presented in Figures 4 and 5, which show experiments from three different cell volumes on six algal species. All three species of Cladocera had a significant effect on the ingestion rate $(\mathrm{p}<0.05)$, while all food concentrations showed a significant difference $(\mathrm{p}<0.05)$, except at food volume of $3.0 \times 10^{6} \mu \mathrm{m}^{3} / \mathrm{mL}$ and $4.5 \times 10^{6} \mu \mathrm{m}^{3} / \mathrm{mL}$ $(\mathrm{p}>0.05)$. The results displayed large fluctuating patterns for A. falcatus (Fig. 1), C. vulgaris (Fig. 4) and M. flos-aquae (Fig. 5), while small fluctuating trends occurred on S. obliquus (Fig. 4) and C. reinhardtii (Fig. 5). On the contrary, Cladocera grazing on $A$. circinalis showed low and almost constant trend throughout the experiment, which means that the rate was small compared with those of the other species of algae 
(Fig. 5). The results of the 3-way ANOVA did not show any significant difference in the Cladocera, algae and concentration $(\mathrm{p}>0.05)$ (Table 1). Based on the fact that at $\mathrm{p}<0.05$, the ingestion rate of algal species varied significantly between the algal concentrations for the eight time intervals.

(a) Daphnia carinata

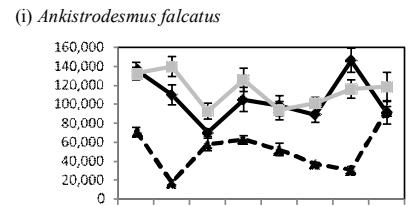

(ii) Scenedesmus obliquus

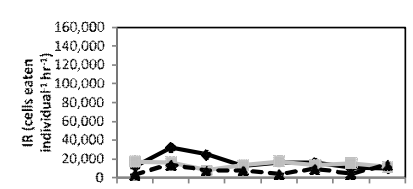

(iii) Chlorella vulgaris

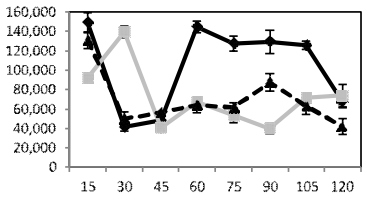

(b) Daphnia lumholtzi
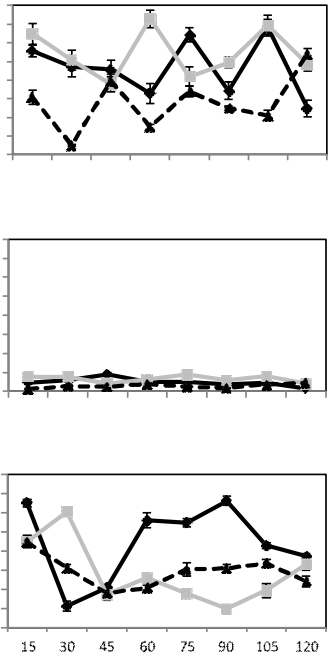

Duration (Mitiutes) (c) Ceriodaphnia cf. quadrangula
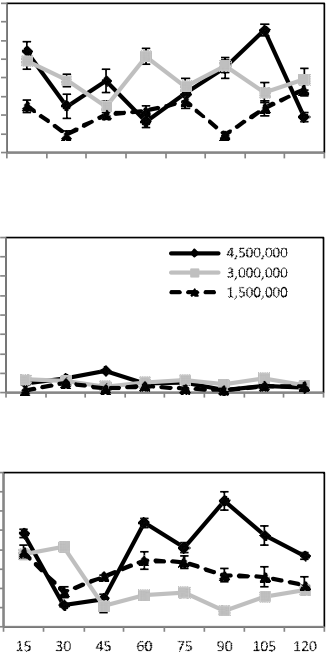

Figure 4. Ingestion rates of (a) Daphnia carinata, (b) D. lumholtzi and (c) Ceriodaphnia cf. quadrangula in the presence of (i) Ankistrodesmus falcatus, (ii) Scenedesmus obliquus and (iii)

Chlorella vulgaris at three volume concentration, calculated for the duration of 15 minutes intervals (0 - 2 hours). Error bars represent the standard error for five experimental replicates

(a) Daphnia carinata

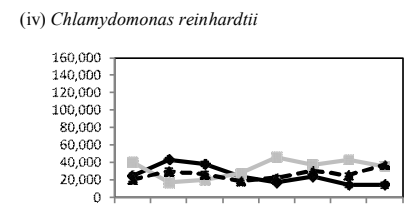

(v) Anabaena circinalis

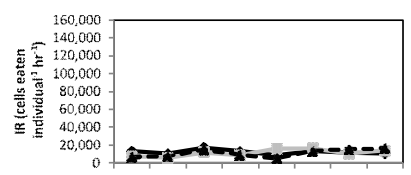

(vi) Microcystis flos-aquae

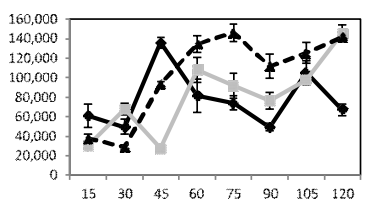

(b) Daphnia lumholtzi
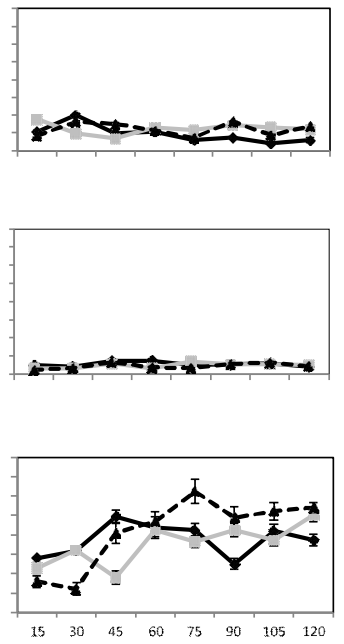

Duration (Mirutes) (c) Ceriodaphnia cf. quadrangula
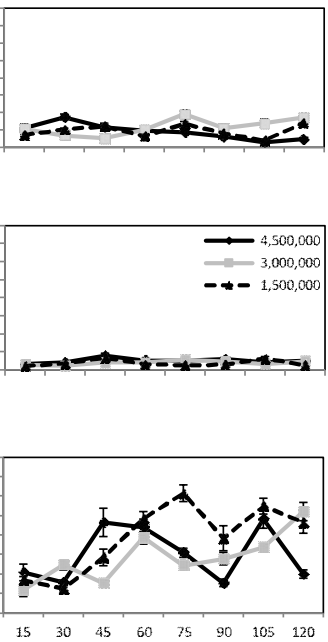

Figure 5. Ingestion rates of (a) Daphnia carinata, (b) D. lumholtzi and (c) Ceriodaphnia cf. quadrangula in the presence of (iv) Chlamydomonas reinhardtii, (v) Anabaena circinalis and (vi) Microcystis flos-aquae at three volume concentration, calculated for the duration of 15 minutes intervals ( 0 - 2 hours). Error bars represent the standard error for five experimental replicat 
Table 1. Results of an ANOVA performed on ingestion rates by time interval

\begin{tabular}{c|c|c|c|c|c}
\hline Source of variation & SS & d.f & MS & F & P \\
\hline Zooplankton & 8.404 & 2 & 4.202 & 68.282 & $0.000^{*}$ \\
Algae & 323.257 & 5 & 64.651 & 1050.545 & $0.000^{*}$ \\
Concentration & 5.770 & 2 & 2.885 & 46.882 & $0.000^{*}$ \\
Duration & 1.395 & 7 & 0.199 & 3.239 & $0.002 *$ \\
Zooplankton x Algae & 0.699 & 10 & 0.070 & 1.136 & 0.331 \\
Zooplankton x Concentration & 0.053 & 4 & 0.013 & 0.214 & 0.931 \\
Zooplankton x Duration & 0.863 & 14 & 0.062 & 1.002 & 0.448 \\
Algae x Concentration & 15.551 & 10 & 1.555 & 25.269 & $0.000^{*}$ \\
Algae x Duration & 20.874 & 35 & 0.596 & 9.691 & $0.000^{*}$ \\
Concentration x Duration & 9.694 & 14 & 0.692 & 11.251 & $0.000^{*}$ \\
Zooplankton x Algae x Concentration & 1.554 & 20 & 0.078 & 1.262 & 0.194 \\
Zooplankton x Algae x Duration & 4.714 & 70 & 0.067 & 1.094 & 0.280 \\
Zooplankton x Concentration x Duration & 1.372 & 28 & 0.049 & 0.796 & 0.767 \\
Algae x Concentration x Duration & 30.152 & 70 & 0.431 & 6.999 & $0.000^{*}$ \\
\hline
\end{tabular}

$* \mathrm{P}<0.05$

\section{Discussion}

This paper focused on the outcomes of grazing rates of three cladocerans species in six single species of algae. The selection of zooplankton and algal species was based on the most common species found in Myponga and South Para Reservoirs. The mean body size of adult animals cultured in the laboratory was larger than those of the ones collected from the reservoirs, probably due to biotic factors such as predation, competition, and disease. To gain the maximum grazing rate, adult size was chosen for the experiments as representatives of all the body sizes present in the culture tanks.

In terms of quality, the six species of algae used were divided into two categories. The first one consisted of $A$. falcatus, $S$. obliquus, $C$. vulgaris and $C$. reinhardtii; all of them are edible algae. The other category included $M$. flos-aquae and A. circinalis, which are potentially toxic blue-green algae that require the cells to break away from the colony and filament before ingestion. In fact, cultured M. flos-aquae grew in smaller colonies than in their natural habitat. This observation corroborates that of Benndorf and Egerer (1981), which say that Microcystis change cell size and/or colony size in the culture. However, results obtained from the experiments may not be representative of their grazing behaviour in their natural environment.

In this experiment, 2-hr incubation periods for all zooplankton species were chosen. This was based on the pilot study, which showed that the zooplankton started to produce offsprings after two hours of incubation. Thus, it would not be relevant to measure feeding rates over longer periods because they might result in measurement bias. Moreover, within a 2-hr period, the animals' guts were believed to be full, thus they would produce faecal while they are simultaneously feeding. Further work on D. magna by Lotocka (2001) revealed that the intestines of adult individuals fed with mixture of $S$. microspina and C. kessleri were completely filled with food within 45 min while $50 \%$ of their guts would be full when exposed to Aphanizomenon flos-aquae after $30 \mathrm{~min}$. Although the duration of this experiment was considered shorter than the findings in past literatures, the results are believed to be sufficiently accurate to determine the feeding rate of zooplankton on the selected foods. Even though in 
previous literatures various grazing methods have been applied, this study chose to measure them via spectrophotometer, as this is the common method to measure cell density. Moreover, the method is simple, quick and yields reliable results. However, the accuracy of the results can be improved by using more replicates of samples, cautiously.

In this study, zooplankton ingested at large amount of food at the beginning of the experiment. Indeed, a higher ingestion rate was expected at the first part of the time interval due to the 24-hr starvation period before the incubation. Acclimatization time was set for $24 \mathrm{hr}$ prior to carrying out the grazing experiment, as some cladocerans would die when starved for more than $24 \mathrm{hr}$. Subsequently, all the starved animals were exposed to a single alga species in different concentrations. Apparently, the animals tested fed at reduced rate at low concentrations, but fed at their maximum rates when exposed to the high concentrations of algae. Ingestion rate was dependent on the density of food until a certain critical concentration, after which the ingestion rate became constant. Previous literatures supported this general pattern (Rothhaupt, 1990; Navarro, 1999). The results of ingestion rate for six species of algae at three cell concentrations affirmed the model by McMahon and Rigler (1965) and agreed with the ILL value obtained by Kersting and Leeuw (1976). Although the observations of algal concentrations may not be sufficient to establish this result absolutely, the result was reliable and able to show how the feeding behaviours changed in different cell concentrations.

$D$. carinata ingestion rate was higher than that of D. lumholtzi and $C$. cf. quadrangula for both blue-green algae M. flos-aquae and A. circinalis. However, the ingestion rates were significantly lower in $A$. circinalis filamants, compared with M. flos-aquae. This may be due to the ability of the grazers to break the small colonies of $M$. flos-aquae, making them easier to graze compared with $50-100 \mu \mathrm{m}$ of A. circinalis filaments during ingestion. Some scientists (Geller and Muller, 1981; Gliwicz and Lampert, 1990) pointed out that it could possibly be due to the size restrictions and rejection, while Infante and Litt (1985) and Hartmann and Kunkel (1991) concluded that the reasons were excessive handling time and poor interception of filaments when compared with non-filamentous algae. Further evidence from observations by Kirk and Gilbert (1992) showed that the presence of Anabaena filaments causes an increase in post-abdominal rejections in the large Daphnia pulex. Therefore, the findings of the present study are in accord with those of previous studies that reported lower grazing rates of $A$. circinalis.

On the other hand, in this study, $C$. cf. quadrangula ingested at the lowest rate when exposed to the single $A$. circinalis suspension, and followed by D. lumholtzi. Thus, clearly the ingestion rate decreased with increasing body size. This has been confirmed by investigations that indicated that small cladocerans are more able to avoid Anabaena cells than larger cladocerans, probably due to their smaller size, which forbids them to ingest the large Anabaena filaments (Kirk and Gilbert, 1992).

Even though the algae were potentially toxic species, the observation on ingestion rate in unialgal suspension of $M$. flos-aquae showed that the three species of Cladocera ingested the potentially toxic form of algal colony (Ismail et al., 2015). Many studies (Fulton, 1988; DeBernardi and Giussani, 1990; Kirk and Gilbert, 1992; Repka, 1996; Kurmayer and Juttner, 1999) have shown subtle toxic effect on fecundity and survival rate of zooplankton fed on cyanobacteria. However, the consequences were not considered in the short-term experiments. Some authors demonstrated that food size affects the differences in the ability of zooplankton to graze on algal species (Persson, 
1985; Borsheim and Andersen, 1987; Urabe et al., 1996). Ingestion rates of A. falcatus $(2.3 \mu \mathrm{m}), C$. vulgaris $(3.3 \mu \mathrm{m})$ and $M$. flos-aquae $(1.9 \mu \mathrm{m})$ by the three species of Cladocera were confirmed to be faster than those of $S$. obliquus $(4.2 \mu \mathrm{m}), C$. reinhardtii $(4.4 \mu \mathrm{m})$ and $A$. circinalis $(5.8 \mu \mathrm{m})$. Undoubtedly, the three species of Cladocera preferred to graze on smaller sized cells. The cell size of $S$. obliquus, $C$. reinhardtii and A. circinalis might be too large for ingestion or to pass through their mouth gapes. According to Gliwicz (1980), the uptake of large particles by zooplankton is limited by the opening width of carapace gap.

Under laboratory conditions, M. flos-aquae grow in smaller colonies than in their natural ecosystems. Moreover, the suspension has been dispersed with strong shaking before the experiments to obtain the maximum ingestion rate. Apparently, the grazers can handle small colonies of $M$. flos-aquae efficiently compared with the filamentous form of $A$. circinalis. Possibly the cells of $M$. flos-aquae are more easily separated and ingested than the filamentous form of $A$. circinalis.

Despite the factor of particle size, differences in the grazability of algal species might be due to several other factors which can be considered, such as cell wall characteristic (Horn, 1981), flagella (DeMott, 1982), spines (Schnack, 1979), gelatinous sheath (McNaught et al., 1980), taste (Poulett and Marsot, 1978) and digestion (Porter, 1976). Knisely and Geller (1986) pointed out that smooth-walled species such as Chlorella would be possibly swept away after they are first captured. On the other hand, A. circinalis is a poor food for zooplankton due to the toxic strain that might affect the growth and the reproduction of Cladocera.

Furthermore, the results of this present study showed that ingestion rate varies with body size. The result is in agreement with those of other studies, which supported the size-efficiency hypothesis described by Brooks and Dodson (1965) which says that larger zooplankton body sizes provide a greater filtering capacity. The largest animal tested, $D$. carinata ingested at the highest rate among all algal species compared with the intermediate-sized $D$. lumholtzi and the small-sized species of $C$. cf. quadrangula. This outcome agrees with the results obtained by Geller and Muller (1981) who indicated that smaller sized grazers may have smaller carapace gaps and mesh sizes.

As observed in the experimental results, feeding behaviour of zooplankton depends on several factors when they are offered as food, algae as a single diet in terms of size, structure, quality and concentration as food. Besides, differences in body size certainly influence grazing efficiency between zooplankton species. Therefore, a combination of these factors may increase or decrease grazability despite the abiotic factors during the experiment.

\section{Conclusion}

The ingestion rate varies depending on the cladocerans' body size and species. In terms of feeding efficiency, larger cladocerans can ingest larger food items than smaller species. Algal size and concentration are major factors affecting the ingestion rate of cladocerans. Different sized algae were grazed at different efficiencies. Feeding on small and large particles appears to be qualitatively different. D. carinata ingested the largest food items most efficiently followed by D. lumholtzi and $C$. cf. quadrangula. The success of $D$. carinata may be explained partly by its ability to feed effectively on a variety of food organisms with a wide spectrum of cell sizes. 
A. circinalis has the lowest rate of ingestion among all grazers. However, all the Cladocera tested do feed on colonies of $M$. flos-aquae at a comparable rate. In the present study, zooplankton feed on both green algae as well as potentially toxic algae, hence, may control the algal biomass in the water column.

In conclusion, the study has determined the feeding rate of zooplankton under laboratory culture conditions, which has been assumed to be close to the natural environment, even though the food concentrations and temperatures varied in both situations. The information on the ingestion of cladocerans can provide useful knowledge for practising efficient management and ideally, for the sustainability of the ecosystem. Undeniably, the results presented here are still limited and considered as preliminary to yielding a better understanding of the grazing and selectivity behaviours of zooplankton in drinking water reservoirs. Thus, it is hoped that future studies will uncover additional information and render some improvements such as using more species of zooplankton and algae at more varied cell concentrations.

Acknowledgements. Appreciation and thanks are due to Peter Baker, Peter Hobson, Steve Amos and Hossain Siddiqui for generously provided cultures of the algae and for advice on maintaining laboratory cultures.

\section{REFERENCES}

[1] Benndorf, J., Egerer, G. (1981): A note on the variability of the diatom Cyclotella meneghiniana (Kiitz) after isolation from the natural environment. - Int. Revue. ges. Hydrobiol. 66: 771-774.

[2] Bogdan, K. G., Gilbert, J. J. (1984): Body size and food size in freshwater zooplankton. Ecology 81: 6427-6431.

[3] Borsheim, K. Y., Andersen, S. (1987): Grazing and food size selection by crustacean zooplankton compared to production of bacteria and phytoplankton in a shallow Norwegian mountain lake. - J. Plankton Res. 9: 367-379.

[4] Brooks, J. L., Dodson, S. I. (1965): Predation, body size and composition of plankton. Science 150: 28-35.

[5] Burns, C. W., Rigler, F. H. (1967): Comparison of filtering rates of Daphnia rosea in lake water and in suspensions of yeast. - Limnol. Oceanogr. 12: 492-502.

[6] Debernardi, R., Giussani, G. (1990): Are blue-green algae a suitable food for zooplankton? An overview. - Hydrobiologia 200/201: 29-41.

[7] Demott, W. R. (1982): Feeding selectivity and relative ingestion rates of Daphnia and Bosmina. - Limnol. Oceanogr. 27: 518-527.

[8] Elser, J. J. (1992): Phytoplankton Dynamics and the Role of Grazers in Castle Lake, California. - Ecology 73: 887-902.

[9] Finkel, Z. V., Beardall, J., Flynn, K. J., Quigg, A., Rees, T. A. V., Raven, J. A. (2010): Phytoplankton in a changing world: cell size and elemental stoichiometry. - J. Plankton Res. 32: 119-137.

[10] Frost, B. W. (1972): Effects of size and concentration of food particles on the feeding behavior of the marine planktonic copepod Calanus pacificus. - Limnol. Oceanogr. 17: 805-815.

[11] Fulton, R. S. I. (1988): Resistance to blue-green algal toxins by Bosmina longirostris. - J. Plankton Res. 10: 771-778.

[12] Geller, W., Muller, H. (1981): The filtration apparatus of Cladocera: Filter mesh-sizes and their implications on food selectivity. - Oceanologia 49: 316-321. 
[13] Gliwicz, Z. M. (1980): Filtering rates, food size selection and feeding rates in cladocerans - Another aspect of interspecific competition in filter feeding zooplankton. - In: Kerfoot, W. C. (ed.) Evolution and ecology of zooplankton communities. New England Press, Hanover.

[14] Gliwicz, Z. M., Lampert, W. (1990): Food thresholds in Daphnia species in the absence and presence of blue-green filaments. - Ecology 71: 691-702.

[15] Hartmann, H. J., Kunkel, D. D. (1991): Mechanisms of food selection in Daphnia. Hydrobiologia 225: 129-154.

[16] Hillebrand, H., Sommer, U. (1996): Nitrogenous nutrition of the potential toxic diatom Pseudonitzschia pungens $f$. multiseries Hasle. - J. Plankton. Res. 18: 295-301.

[17] Hillebrand, H., Durselen, C.-D., Kirschtel, D., Pollingher, U., Zohary, T. (1999): Biovolume calculation for pelagic and benthic microalgae. - J. Phycol. 35: 403-424.

[18] Hoff, F. H., Snell, T. W. (1987): Plankton Culture Manual. - Florida Aqua Farms Inc.

[19] Horn, W. (1981): Phytoplankton losses due to zooplankton grazing in a drinking water reservoir. - Internat. Revue. ges. Hydrobiol. 66: 787-810.

[20] Infante, A., Litt, A. H. (1985): Differences between two species of Dapnhia in the use of 10 species of algae in Lake Washington. - Limnol. Oceanogr. 30: 1053-1059.

[21] Ismail, A. H., Mills, S., Recknagel, F. (2015): A new rotating tumbler apparatus for zooplankton grazing in laboratory. - Ekoloji 24(97): 54-59.

[22] Kersting, K., Leeuw, W. V. D. (1976): The use of the coulter counter for measuring the feeding rates of Daphnia magna. - Hydrobiologia 49: 233-237.

[23] Kilham, S. S., Kreeger, D. A., Lynn, S. G., Goulden, C. E., Herrera, L. (1998): COMBO: A defined freshwater culture medium for algae and zooplankton. - Hydrobiologia 377: 147-159.

[24] Kirk, K. L., Gilbert, J. J. (1992): Variation in herbivore response to chemical defenses: Zooplankton foraging on toxic cyanobacteria. - Ecology 73: 2208-2217.

[25] Knisely, K., Geller, W. (1986): Selective feeding of four zooplankton species on natural lake phytoplankton. - Oecologia 69: 86-94.

[26] Kurmayer, R., Juttner, F. (1999): Strategies for the co-existence of zooplankton with the toxic cyanobacterium Planktothrix rubescens in Lake Zurich. - J. Plankton Res. 21: 659683.

[27] Lampert, W., Fleckner, W., Rai, H., Taylor, B. E. (1986): Phytoplankton control by grazing zooplankton: A study on the spring clear-water phase. - Limnol. Oceanogr. 31: 478-490.

[28] Lotocka, M. (2001): Toxic effect of cyanobacterial blooms on the grazing activity of Daphnia magna Straus. - Oceanologia 43: 441-453.

[29] McMahon, J. W., Rigler, F. H. (1965): Feeding rate of Daphnia magna Straus in different foods labeled with radioactive phosphorus. - Limnol. Oceanogr. 10: 105-113.

[30] McNaught, D. C., Griesmer, D., Kennedy, M. (1980): Resource characteristics modifying selective grazing in copepods. - In: Kerfoot, W. C. (ed.) Evolution and ecology of zooplankton communities. University Press, New England.

[31] Navarro, N. (1999): Feeding behaviour of the rotifers Brachionus plicatilis and Brachionus rotundiformis with two types of food: Live and freeze-dried microalgae. - J. Exp. Mar. Biol. Ecol. 237: 75-87.

[32] Persson, G. (1985): Clearance rates of crustacean microfiltrators: The nature of in-situ rate depressions in a fertilized oligotrophic lake in the Kuokkel area, Northern Sweden. Internat. Revue ges. Hydrobiol. 70: 335-358.

[33] Porter, K. G. (1976): Enhancement of algal growth and productivity by grazing zooplankton. - Science 192: 1332-1334.

[34] Poulet, S. A., Marsot, P. (1978): Chemosensory grazing by marine calanoid copepods (Arthropoda: Crustacea). - Science 200(4348): 1403-1405. 
[35] Repka, S. (1996): Inter- and intra specific differences in Daphnia life histories in response to two food sources: The green alga Scenedesmus and the filamentous cyanobacterium Oscillatoria. - J. Plankton Res. 18: 1213-1223.

[36] Rippka, R., Deruelles, J., Waterbury, J. B., Herdman, M., Stanier, R. Y. (1979): Generic assignments, strain histories and properties of pure cultures of cyanobacteria. - J. Gen. Microbiol. 111: 1-61.

[37] Rothhaupt, K. O. (1990): Changes of the functional responses of the rotifers Brachionus rubens and Brachionus calyciflorus with particle sizes. - Limnol. Oceanogr. 35: 24-32.

[38] Schnack, S. B. (1979): Feeding of Calanus helgolandieus on phytoplankton mixtures. Mar. Ecol. Prog. Ser. 1: 41-47.

[39] Tilman, D., Kilham, S., Kilham, P. (1982): Phytoplankton community ecology: The role of limiting nutrients. - Annu. Rev. Ecol. Syst. 13: 349-372.

[40] Urabe, J., Kawabata, K., Nakanishi, M., Shimizu, K. (1996): Grazing and food size selection of zooplankton community in Lake Biwa during BITEX' 93. - Jpn. J. Limnol. 57: 27-37.

[41] Wirtz, K. W. (2013): How fast can plankton feed? Maximum ingestion rate scales with digestive surface area. - J. Plankton. Res. 35(1): 33-48. 